\title{
Monoclonal Antibody 3622W94
}

National Cancer Institute

\section{Source}

National Cancer Institute. Monoclonal Antibody 3622W94. NCI Thesaurus. Code C2470.

A humanized murine monoclonal antibody (MoAb) against the 17-1A antigen, with potential adjuvant therapeutic properties in colorectal cancer. 17-1A antigen (EpCAM), a human epithelial cell adhesion molecule, expresses in a variety of carcinoma tissues, such as those of colon and breast carcinomas. Immunization with MoAb 3622W94 may elicit immune responses, which could result in eradicating tumor cells expressing 17-1 A antigen. 